\title{
Scientists and Government Research Information
}

W Hen ScIentist Alpha, who is engaged in research at the University of Beta or at Gamma Laboratories, Inc., seeks conventionally-published literature in any field or phase of science, he has available a number of reliable, well-established channels to facilitate his quest. For one thing, the scope of the contents of most scientific journals is more or less definitely defined. Also, professional periodicals are published in volumes and numbers and usually carry annual author and subject indexes. In addition, various abstracting and indexing services provide a secondary approach to the contents of these publications. Thus, Dr. Alpha-or his technical librarian-can conduct the search along quite well-lighted and adequately-mapped publication and dissemination highways.

But suppose our scientist wishes to determine whether or not any results of significance in his field of research interest have appeared in the body of printed and near-print material we call scientific report literature. It is estimated-probably conservatively-that upwards of 20,000 unclassified scientific reports are issued annually by the hundreds of laboratories engaged wholly or partially in Federallysupported scientific research. With the exception of certain intra-laboratory series, these documents follow no pattern even vaguely resembling the volume-number system of journals. Very few scientific reports are abstracted or indexed by the standard secondary publication media, and, in general, each issuing agency estab-

Dr. Gray is program director, Office of Scientific Information, National Science Foundation. lishes its own rules for their preparation. They are subject to little standardization of style, format, or stature of content and have as almost their only common attributes those of being technical and of appearing as pamphlets with rectangular pages. Here, Scientist Alpha is faced with a search problem which is much more complex than the one that confronted him in the first instance.

To make this scientific report literature approximately as available to the average research scientist as is conventionally-published material is the principal objective of the Government Research Information program of the National Science Foundation. To describe this program and the thinking that preceded its initiation is the purpose of this paper.

Before deciding to initiate a report information service with the objective stated above, the Foundation considered three principal questions:

1. Do these thousands of unclassified scientific reports contain substantial amounts of significant scientific information?

2. If so, does an appreciable fraction of such information fail to appear reasonably promptly in regularly-published form?

3. How well does existing machinery for announcing and disseminating scientific reports meet the needs of research scientists?

Regarding the first question, the very circumstances under which these documents are prepared lead one to expect them to contain appreciable quantities of worth-while scientific information. Many-perhaps most-actually are reports by a contractor to his contracting 
agency on work accomplished with that agency's support. Since so large a fraction of scientific research today is at least partly supported by some branch of the Federal Government, much of what is newest and most important in current scientific experimentation first sees the light of publication day in technical reports. As evidence of a more concrete nature, one can cite certain statistics on the operation of existing information dissemination activities. During the fiscal year 1955, the Armed Services Technical Information Agency (ASTIA), which serves only Government agencies and contractors and handles only Department of Defense reports, supplied over 280,000 technical reports on request to its more than 3,500 users. It also prepared, again on request, almost 1,400 separate bibliographies of scientific reports listing a total of over 150,000 items. The Office of Technical Services of the Department of Commerce, which announces and offers for sale certain technical reports on Governmentsupported research and development, sold some 172,000 such documents during 1955. Similar data can be cited for the information services of the Atomic Energy Commission and the National Advisory Committee for Aeronautics. Consequently, the National Science Foundation had little doubt but what an affirmative reply could be given to the first question.

The answer to the second question seemed quite definitely to be that an appreciable fraction of the information in scientific reports does not appear promptly in conventional publications. One study of approximately 1,200 unclassified Department of Defense reports showed that nothing whatever had been published after four years from about onefourth of the reports which the authors themselves believed contained "publishable" information. All such information in somewhat fewer than half of the reports have appeared in print, but with time lags from a few weeks to four years; the average time between report issuance and journal publication for the sample studied was about a year and a half. Furthermore, among the data which journal editors ordinarily would not find acceptable for publication is a great deal of information which potentially is sufficiently useful to research scientists to warrant taking special steps to insure its continuing availability. Such material includes, for example, detailed tables and other data which must be eliminated or drastically condensed to meet journal space requirements and negative experimental results which editors ordinarily do not publish but which, if adequately disseminated, often can prevent costly repetition of unsuccessful investigations.

Study of the point raised in the third question led to the conclusion that existing report announcement and dissemination activities do not fully meet the needs of U. S. research scientists in the field of Government research information. This is not because of any failure by existing activities to fulfill their missions; the situation stems rather from the nature of those missions. For example, the information branches of the Atomic Energy Commission and the National Advisory Committee for Aeronautics quite properly are organized to serve their respective departments and contractors. The Armed Services Technical Information Agency, as noted previously, deals only with Department of Defense reports and must limit its services to the Department, its contractors, and other Government agencies. The Office of Technical Services comes the nearest to meeting the objective which is the Foundation's concern, but its report coverage has been predominantly in the development rather than the research field and its users have been largely from industry. The net result has been that the scientist engaged in research not specifically supported under Government contract has had no channel, established specifically with his needs in mind, through which he can learn whether or not reports are being issued 
on Government-supported research in his fields of interest and, if so, how copies can be consulted or obtained. It is this gap which the Foundation's Government Research Information program is trying to fill.

As has already been stated, the fundamental objective of the Government Research Information program is the achievement of maximum availability to U. S. research scientists of the significant, unclassified information in scientific reports on Federally-supported research. In the Foundation's thinking, satisfying this objective requires as a minimum that scientists be provided with three services:

1. Automatic announcement of the bulk of Government research reports by means of a bulletin or other medium to which they can subscribe; this service should list available reports, indicate how copies can be obtained, and, if possible, provide abstracts or annotations.

2. A reference collection of reports on unclassified, Government-supported research-together with appropriate catalogs - which is available to everyone on the same basis as are the collections of a conventional reference library.

3. A consultation service to assist them in learning whether or not unclassified scientific reports are being issued in their fields of interest and, if so, how copies can be obtained.

The Foundation recognized that the kinds of machinery necessary to provide some of these services already exist in certain of the information agencies referred to previously. It resolved, therefore, in its approach to this problem, to make maximum use of such activities, supplementing them wherever feasible in preference to initiating new and possibly overlapping projects. As a result, the Government Research Information program as now set up specifically involves two grants to existing Governments agencies and the operation of one activity within the Foundation.

To meet the first of the three min- imum requirements - that of an automatic report announcement service-the Foundation is providing supplemental support to an existing Government agency, the Office of Technical Services (OTS) of the Department of Commerce. ${ }^{1}$ For several years, OTS has published the monthly subscription journal, U.S. Government Research Reports (USGRR), which is an annotated listing of technical reports on federally-supported research and development. It has been announcing some 6,000 such documents annually. As noted previously, the reason this service did not already fully meet the report announcement needs of research scientists stemmed from the pattern of its coverage. Although there was no specific policy of excluding basic science material, the circumstances of OTS' support and the fact that OTS' users were primarily from industry combined to make its emphasis in this area considerably less than that in engineering and the applied sciences. The Foundation's supplementary support, however, is enabling OTS to carry on a vigorous acquisition program among Government agencies in the basic research fields and thereby increase its coverage in this area to a level commensurate with that of its applied science coverage in the past.

The objective of OTS and the Foundation in this phase of the program is for the OTS journal eventually to include in its coverage every significant, unclassified scientific report on Government-supported research and to make each such report available for purchase in some economic, legible form. USGRR provides an ideal announcement and dissemination channel for smaller agencies whose technical reports really should be made generally available but whose report reproduction and handling facilities are limited. Such an agency can have its reports announced in this journal without having to assume

1 Detailed information on the operation of OTS can be obtained from the office of Technical Services, Department of Commerce, Washington 25, D.C. 
any responsibility for filling requests for copies, since the announcement can indicate that photo-reproductions are available for purchase through the regular OTS channels.

It seemed to the Foundation that the Library of Congress was by far the most appropriate agency to provide the report reference service which is the second minimum requirement mentioned above. The Library's holdings already contained large numbers of unclassified scientific reports on Federally-sponsored research, and such documents were being received regularly from various agencies. Also, and more important, providing biblographic services of the kind envisioned here is a field in which the Library has had decades of experience and is recognized as a world authority. Consequently, the two agencies entered into an agreement whereby the Foundation provides sufficient financial support to permit the Library to extend its normal bibliographic treatment of scientific reports to include establishing these documents on a basis such that scientists and others can consult them in the same way they now use books in a reference library. Readers have free access to the catalogs covering these reports, and reference assistants bring them copies of any of the documents they wish to read. Anyone wishing a copy for retention will be referred to OTS, if it stocks the report, or to the Library's Photo-duplication Service, if a photo-reproduction is desired. ${ }^{2}$

Close liaison is being maintained between the Library of Congress and Office of Technical Services phases of the program, and it is anticipated that, once the activity is fully established, the former's "consultation" collection will contain as a minimum copies of all reports which the latter announces in its journal. Actually, the two agencies have had a coop-

\footnotetext{
2 Detailed information on the operation of the LC report reference activity can be obtained from the Science Division, Library of Congress, Washington 25 , D.C.
}

erative arrangement for several years under which the Library's Photo-duplication Service fills all requests for microfilm or photostat copies of documents listed in USGRR. Thus, even before the Foundation's program was thought of, OTS had been sending the Library copies of most of the reports announced in its journal.

The third minimum requirement - that of providing a consultation and steering service on Government scientific reports -is being met within the Foundation's Office of Scientific Information in a section called "Government Research Information Clearinghouse." Here the attempt is being made to provide a center to which any scientist can turn for information on such matters as where in Government or under Government sponsorship unclassified research is going on in any given subject field; whether unclassified reports have been or are being issued on such work; whether, and if so how, the requestor can either see or obtain copies of these reports; and the like. The Clearinghouse neither maintains inventories of copies of reports nor obtains and retransmits documents. In other words, it is a center for providing information about Government reports but not one for disseminating the reports themselves. Requests for information are accepted by telephone, by mail, or in person. Letters should be addressed to the Government Research Information Clearinghouse, Office of Scientific Information, National Science Foundation, Washington 25, D.C.

The field of Government scientific report literature is extensive and complex and largely lacking in the kind of over-all guidebook and publications "Baedeker" which exists for conventionally-published material. Therefore, the principal reference tool of the Clearinghouse must be the personal knowledge and experience of its reference staff. The present small group is composed of individuals 
who for some years have been engaged in reference work in this field. Supplementary bibliographic aids include project summaries, accession lists, bibliographies, classification systems, organization charts, and, of particular importance, personal contacts with technical librarians and other information experts in Government agencies which conduct and sponsor scientific research.

Because this paper is being written only a few weeks after the initial announcement of the Clearinghouse, no very extensive body of actual experience can be called upon as a basis for predicting the general nature of the requests the group will be asked to handle. Even the relatively small number received to date, however, have covered a fairly wide range of subject matter and include queries about Government reports in the fields of chemistry of animal venoms, glass-to-metal seals, plant physiology, indium, experimentally-induced tumors in mice, pulmonary physiology, metal casting, medicinal chemistry, diatoms, and others.
In summary, the "food, shelter, and clothing" of the scientist's technical information needs may be said to be the answers to "What exists?," "Where is it?" and "How can I get it?" In the field of conventionally-published material, primary and secondary journals, together with various well-established associated aids, long have been providing these necessities of scientific information life. Through its relatively new Government Research Information program, as described above, the National Science Foundation hopes in the course of time to make equally as accessible to U. S. scientists the contents of Government scientific report literature. Because certain phases of the task already are being partially performed as by-products of existing operations, it believes this objective can be accomplished best by combining supplementary support of such going projects in other agencies with the initiation of new programs where gaps exist. It is on this basis that the program is being planned and conducted.

\section{Lilly Foundation Grant for College Libraries}

A grant of $\$ 26,000$ has been made to the American Library Association by the Lilly Endowment, Inc., of Indianapolis, Ind., to be distributed in sub-grants to four-year colleges and universities in Indiana, Kentucky, Ohio, Michigan, and Illinois. The purpose of the grant is "to promote more extensive and imaginative use of library resources by undergraduate students." The grants will be administered by the Committee on Foundation Grants of the Association of College and Reference Libraries, which will prepare a full statement of the types of programs for which grants may be made. This statement, with application forms, will be sent to all four-year institutions of higher education, both public and private, in the five states. This material is expected to be mailed out before the Spring of 1957 so that the grants may be made in April or May and the programs get under way the following Fall. 